\title{
Cost of Catheter Versus Surgical Ablation in the Wolff-Parkinson-White Syndrome
}

\author{
Michael de Buitleir, MD, Edward L. Bove, MD, Stephen Schmaltz, MPH, Alan H. Kadish, MD, \\ and Fred Morady, MD
}

In this retrospective study of 22 patients with the Wolff-Parkinson-White (WPW) syndrome, the cost of catheter ablation in 11 patients was compared with that of surgical ablation in another 11 patients. All patients in the catheter ablation group had a posteroseptal accessory pathway; in the surgical group, 5 patients had a left lateral accessory pathway, 3 had a left lateral and posteroseptal accessory connection and 3 had a right-sided pathway. Catheter ablation was successful in 8 of 11 patients $(73 \%)$. In the surgical group, the accessory pathway was interrupted successfully in all patients $(100 \%)$. The mean duration ( \pm standard deviation) of hospitalization was $6 \pm 2$ days in the catheler ablation group and $8 \pm \mathbf{4}$ days in the surgical group. The mean cost/patient, expressed in 1988 dollar values, was $\$ 14,116 \pm 4,493$ in the catheter ablation group and $\$ 34,175 \pm 5,434$ in the surgical ablation group ( $p<0.0001$ ). The mean time lost from work or school was $10 \pm 5$ days in the catheter ablation group and $60 \pm 16$ days in the surgical group ( $p<0.01$ ). Catheter ablation is significantly less expensive than surgical ablation of accessory pathways. Assuming that all patients in whom catheter ablation is unsuccessful subsequently undergo successful surgical ablation, the mean cost of definitive therapy in the catheter ablation group $(\$ 24,382 \pm \mathbf{4 , 7 4 1})$ is still significantly lower than the cost in the surgical group $(\$ 34,175$; $p<0.001$ ). An additional economic advantage of catheter ablation is that the mean time lost from work or school is 10 days compared to 60 days with surgical ablation.

(Am J Cardiol 1990;66:189-192)

From the Department of Internal Medicine, Division of Cardiology and Clinical Research Center, and the Department of Cardiothoracic Surgery, University of Michigan Medical Center, Ann Arbor, Michigan. Manuscript received December 18, 1989; revised manuscript received and accepted March 7, 1990.

Address for reprints: Michael de Buitleir, MD, Division of Cardiology, University of Michigan Hospital, UH B1/F245, 1500 East Medical Center Drive, Ann Arbor, Michigan 48109.
A considerable number of patients with the WolffParkinson-White (WPW) syndrome require definitive therapy for their condition because of intractable symptoms or intolerance to medications. In addition, the majority of patients with the WPW syndrome are young and otherwise healthy and a definitive ablation procedure offers them the possibility of a complete cure from a potentially life-threatening condition. Catheter ablation has been demonstrated to be an effective therapy for interrupting posteroseptal accessory pathways ${ }^{1.2}$ and surgery is highly effective for all accessory pathways. ${ }^{3,4}$ Prior studies have examined the results of catheter ablation ${ }^{2,5}$ and surgical ablation ${ }^{3,4}$ for the WPW syndrome but no studies to date have performed a direct cost comparison of the 2 modes of therapy. We compared the overall cost of catheter and surgical ablation in patients with the WPW syndrome.

\section{METHODS}

Study design: This was a retrospective study of 22 consecutive patients who underwent either catheter ablation or surgical ablation for the treatment of the WPW syndrome between 1984 and 1988 at the University of Michigan Medical Center. Case records were reviewed and the following patient data were extracted: age, sex, location of the accessory pathway, duration of hospital admission after the index ablation procedure and associated complications. In all patients the day of the procedure was regarded as day 1 for the calculation of costs. Assessment of success or failure of the procedure was made at the time of hospital discharge.

Catheter ablation: Eleven patients aged 15 to 56 years (mean \pm standard deviation $34 \pm 13 ; 6$ men) underwent catheter ablation. Each patient underwent a thorough electrophysiologic evaluation that demonstrated the typical features of the WPW syndrome. ${ }^{6}$ All the patients in the catheter ablation group had a posteroseptal accessory pathway and all provided informed consent to undergo the procedure. The technique used for posteroseptal ablation at this institution has been described in detail previously. ${ }^{2}$ After the procedure the patients were admitted to the coronary care unit for 24 to 48 hours of intensive cardiac monitoring. Subsequently, patients were observed in the stepdown cardiac unit for another 3 to 4 days before discharge from hospital. All patients had 3 serial cardiac enzyme determinations performed within the first 24 hours to detect myocardial damage. Daily 12-lead electrocardiograms were performed during the first few days and on the day of hospital discharge. All patients had a resting equilibrium- 
gated radionuclide ventriculogram, a technetium- $99 \mathrm{~m}$ pyrophosphate scan, a cross-sectional echocardiogram and a 24-hour ambulatory electrocardiogram performed during their hospitalization. Five of the catheter ablations were performed in 1988,3 were performed in 1987, 2 in 1985 and 1 in 1984.

Catheter ablation was completely successful in 7 of 11 patients and partially successful in 1 other patient, yielding an overall success rate of $73 \%$. The mean number of shocks that each patient received was $2.4 \pm 0.7$ and the mean stored energy of each shock was $258 \pm 51$ $\mathrm{J}$. The mean cumulative energy/patient was $613 \pm 223$ J. In the 7 patients with complete success the delta waves on the 12-lead electrocardiogram were abolished by the procedure and reentrant tachycardia could no longer be induced. Success was achieved in 6 of these 7 patients (Table I; patients 2, 3, 5, 6, 8 and 10) after 2 shocks at the first catheter ablation session. In the seventh patient (1), success was achieved after another 2 shocks at the second catheter ablation session. In the 1 patient with a partial success, the delta waves recurred within 48 hours; at a follow-up electrophysiology test, orthodromic reciprocating tachycardia was inducible but the rate was 160 beats $/ \mathrm{min}$, compared to 210 beats/min in the baseline state. A second attempt at catheter ablation was not undertaken in this patient because of the inability to recanulate the coronary sinus. The mean length of hospitalization in the catheter ablation group was $6 \pm 2$ days.

The only procedural complication was acute pericardial tamponade in 1 of the 3 patients in whom catheter ablation was unsuccessful. This was drained percutaneously and the patient was stabilized without recourse to emergent surgery. Subsequently, the patient underwent successful surgical ablation. No patient died from the attempt at catheter ablation.

Surgical ablation: Eleven patients aged 17 to 55 years (mean $31 \pm 13 ; 9$ men) underwent surgical ablation. All patients underwent a thorough preoperative electrophysiologic evaluation; 5 were found to have a left lateral accessory pathway, 3 had a left lateral and posteroseptal accessory pathway and 3 had a right-sided accessory pathway.

The technique used for the operative ablation of accessory atrioventricular connections in the WPW syndrome has been described in detail previously. ${ }^{3}$ Surgical ablation was successful in all 11 patients $(100 \%)$. The mean duration of hospitalization was $8 \pm 4$ days in the surgical ablation group; this was not significantly different from the value of $6 \pm 2$ days in the catheter ablation group. Minor complications occurred in 2 patients and consisted of a persistent serous drainage from the median sternotomy wound in 1 patient and transient atrioventricular block and atrial fibrillation in a second patient. Ten of the 11 surgical ablations were performed in 1988 and 1 was performed in 1987.

Cost analysis: In this study the day of the ablation procedure was regarded as day 1 for the calculation of costs and all expenses incurred before that date were excluded from the analysis. This method of analysis was
TABLE I Cost of Catheter Ablation and Duration of Hospitalization in 11 Patients

\begin{tabular}{|cclll|}
\hline Pt & $\begin{array}{l}\text { Hospital } \\
\text { Charge }(\$)\end{array}$ & $\begin{array}{l}\text { Physician } \\
\text { Charge }(\$)\end{array}$ & $\begin{array}{l}\text { Total } \\
\text { Charge }(\$)\end{array}$ & $\begin{array}{l}\text { Hospital } \\
\text { Stay (days) }\end{array}$ \\
\hline 1 & 15,463 & 9,323 & 24,786 & 12 \\
2 & 8,624 & 4,670 & 13,294 & 7 \\
3 & 6,294 & 5,252 & 11,546 & 4 \\
4 & 8,300 & 7,035 & 15,335 & 4 \\
5 & 6,028 & 5,135 & 11,163 & 4 \\
6 & 8,820 & 4,621 & 13,441 & 7 \\
7 & 7,778 & 4,641 & 12,419 & 6 \\
8 & 9,036 & 4,327 & 13,363 & 6 \\
9 & 13,734 & 6,104 & 19,838 & 8 \\
10 & 5,909 & 4,779 & 10,688 & 5 \\
11 & 5.099 & 4,311 & 9,410 & 3 \\
Mean & 8,644 & 5,472 & 14,116 & 6 \\
SD & 3,254 & 1,517 & 4,493 & 2 \\
\hline SD = standard deviation. & \multicolumn{5}{c}{} \\
\hline \multicolumn{5}{|c}{} \\
\hline
\end{tabular}

TABLE II Approximate Annual Inflation Rates in Hospital and Physician Charges at the University of Michigan Medical Center Between 1984 and 1988

\begin{tabular}{|lll|}
\hline & \multicolumn{2}{l|}{ Inflation Rates } \\
\cline { 2 - 3 } & $\begin{array}{l}\text { Hospital } \\
\text { Charges }(\%)\end{array}$ & $\begin{array}{l}\text { Physician } \\
\text { Year }\end{array}$ \\
\hline 1985 & 6.0 & Fees $(\%)$ \\
1986 & 5.8 & 5.5 \\
1987 & 5.6 & 4.7 \\
1988 & 5.3 & 7.4 \\
\hline
\end{tabular}

TABLE III Cost of Surgical Ablation and Duration of Hospitalization in 11 Patients

\begin{tabular}{|clrlr|}
\hline Pt & $\begin{array}{l}\text { Hospital } \\
\text { Charge }(\$)\end{array}$ & $\begin{array}{l}\text { Physician } \\
\text { Charge }(\$)\end{array}$ & $\begin{array}{l}\text { Total } \\
\text { Charge }(\$)\end{array}$ & $\begin{array}{l}\text { Hospital } \\
\text { Stay (days) }\end{array}$ \\
\hline 1 & 19,623 & 8,954 & 28,577 & 6 \\
2 & 36,096 & 10,064 & 46,160 & 15 \\
3 & 21,176 & 8,562 & 29,738 & 6 \\
4 & 29,126 & 10,331 & 39,457 & $/$ \\
5 & 20,556 & 9,002 & 29,558 & 6 \\
6 & 21,237 & 9,946 & 31,183 & 5 \\
7 & 31,236 & 8,818 & 40,054 & 17 \\
8 & 22,793 & 10,033 & 32,826 & 6 \\
9 & 23,039 & 9,452 & 32,491 & 7 \\
10 & 23,719 & 9,536 & 33,255 & 7 \\
11 & 22,368 & 10,259 & 32,627 & 6 \\
Mean & 24,633 & 9,542 & 34,175 & 8 \\
SD & 5,218 & 628 & 5,434 & 4 \\
\hline SD = standard deviation. & & & \\
\hline
\end{tabular}

adopted in an attempt to make the 2 groups as comparable as possible and to exclude all costs that were not directly related to the ablation procedure.

The total cost was determined based on the direct cost to the patient of the ablation and subsequent hospitalization. The direct cost of the ablation procedure was calculated by combining data from 2 sources. The patient accounts department provided the total hospital bill that each patient received; this included charges for room and board, use of the operating room and electrophysiology laboratory, $x$-rays and blood tests. The independent physician associate groups within the medical 
center (e.g., internal medicine, thoracic surgery, anesthesiology and radiology) provided data regarding physician fees.

To allow a direct comparison between the 2 groups, all the cost data in the study were adjusted to $1988 \mathrm{dol}-$ lar values. The hospital charges were adjusted using the average annual inflation rate for salaries and commodities at the University of Michigan Medical Center (Table II). The inflation correction factor for physician fees was obtained from the Physicians Services Index of the Consumer Price Index using the 3-month period February through April (Table II).

An adjusted estimate for the mean cost of therapy in the catheter ablation group was derived by calculating the projected cost of additional surgical therapy in patients with unsuccessful catheter ablation. This was necessary because the 3 patients in whom catheter ablation was unsuccessful later would have required surgery for definitive therapy.

An estimate of the indirect cost was obtained by examining the time that each patient lost from work or school as a result of the procedure. These data were obtained retrospectively by means of telephone interviews with each of the patients. An estimate of lost income as a result of time lost from work was made using the most recent average annual per capita personal income in the United States of $\$ 15,495 . ?$

Statistical analysis: The unpaired Student $t$ test was used to compare all the cost data and the Wilcoxon rank sum test was used to compare the time lost from work in the 2 groups. An approximate variance for the adjusted cost of successful therapy in patients with unsuccessful catheter ablation was derived using the propagation of error formulas. ${ }^{8} \mathrm{~A}$ p value $<0.05$ was considered significant and all data are expressed as mean \pm 1 standard deviation.

\section{RESULTS}

Direct costs: In this group of 22 patients, the total cost of catheter ablation, $\$ 14,116 \pm 4,493$, was significantly lower than the cost of surgical ablation, $\$ 34,175$ $\pm 5,434(p<0.0001)$ (Tables I and III). In the catheter ablation group, hospital charges made up $61 \%$ and physician fees $39 \%$ of the total cost. In the surgical ablation group hospital charges accounted for $72 \%$ and physician fees $28 \%$ of the total cost.

The mean hospital charge in the catheter ablation group, $\$ 8,644 \pm 3,254$, was significantly lower than the hospital charge in the surgical ablation group, $\$ 24,633$ $\pm 5,218(\mathrm{p}<0.0001)$. Further analysis of the total hospital charge in the surgical ablation group revealed that $85 \%$ of the cost was related to the use of the operating room or intensive care facilities. The mean physician fee of $\$ 5,472 \pm 1,517$ in the catheter ablation group was also significantly lower than the value in the surgical group, $\$ 9,542 \pm 628(\mathrm{p}<0.0001)$. The total physician fee in the surgical group was composed of the surgeon's fee $(54.7 \%)$, the cardiologist/electrophysiologist's fee $(31.5 \%)$, the anesthetist's fee $(13.2 \%)$ and the radiologist's fee $(0.6 \%)$. The physician charge in the catheter ablation group consisted almost entirely of the cardiologist/electrophysiologist fee.

Projected cost of successful therapy in patients with unsuccessful catheter ablation: Assuming that each of the patients in whom catheter ablation was ineffective then underwent surgical ablation, the adjusted estimate of the mean cost of successful therapy in the catheter ablation group would be $\$ 24,382 \pm 4,741$. This is $28 \%$ lower than the mean total cost of $\$ 34,175 \pm$ 5,434 in the surgical ablation group and the difference is highly significant ( $p<0.001)$.

Return to work or school: Complete data regarding return to work or school were available for all patients in the catheter ablation group. The mean time lost from work because of the procedure was $10 \pm 5$ days. Complete data were available for all but 1 of the patients in the surgical ablation group and the mean time lost from work or school because of the procedure was $60 \pm 16$ days. The difference between the 2 was significant ( $p$ $<0.01$ ). The projected loss of wages/patient in the catheter ablation group was $\$ 424$, compared to $\$ 2,547$ in the surgical ablation group.

\section{DISCussion}

Catheter versus surgical ablation: This study demonstrates that surgical ablation is significantly more expensive than catheter ablation for definitive treatment of the WPW syndrome. The higher cost of surgical ablation is due to higher physician fees and hospital charges, especially the latter. A large part of the increased cost of hospitalization in patients undergoing surgical ablation results from operating room and intensive care related charges. For obvious reasons, these costs are not incurred in the majority of patients undergoing catheter ablation and this factor contributes appreciably to the lower cost of the catheter method. Even if due allowance is made for patients who fail catheter ablation to undergo surgery, the total cost of catheter ablation is still considerably lower than that of surgical ablation.

The success rate of catheter ablation in interrupting accessory pathways is approximately $70 \% .^{2}$ This compares with a success rate approaching $100 \%$ in recently published surgical scrics. ${ }^{3.4}$ Paticnts in whom catheter ablation fails, however, can subsequently undergo surgical ablation with the same expectation of success as patients who have never undergone an attempt at catheter ablation. Thus, a failed catheter ablation does not limit a patient's options in relation to surgery at a later time.

To date, catheter ablation has been used almost exclusively to ablate posteroseptal accessory pathways, which account for about $33 \%$ of all accessory atrioventricular connections. In contrast, surgical ablation is equally effective at interrupting accessory pathways at all locations within the heart. In a recent study, ${ }^{5}$ Warin et al reported that the catheter technique can be used successfully to ablate accessory pathways at multiple locations within the heart. However, this procedure is technically difficult and in many cases involves more than 1 session in the cardiac electrophysiology laboratory. Therefore, the cost analysis outlined in the present 
report cannot be extrapolated to catheter ablation of free-wall accessory pathways.

Return to work: One of the notable findings of our study is that patients who undergo catheter ablation are able to resume normal activities soon after discharge from the hospital. This contrasts with surgical ablation, which is associated with greater morbidity and the need for a longer convalescent period. Although the resulting cost saving demonstrated in our study seems relatively small, we may have underestimated this factor by basing our calculations on the average per capita personal income in the United States. At any rate, the indircct cost saving from rapid return to full-time employment after catheter ablation represents an additional economic advantage of this procedure.

Duration of hospitalization: The mean length of hospitalization for the 2 procedures was similar in our study. However, there was a tendency for the length of hospital stay in the catheter ablation group to be shorter with the more recent procedures. Because catheter ablation is still regarded as investigational, all patients in our study were monitored intensively and had a variety of costly investigations performed during their admission. However, many of these investigations may no longer be appropriate today and our current practice differs from that described in this study. For example, a patient who underwent catheter ablation of a posteroseptal accessory pathway in November 1989 was discharged from the hospital after 3 days. During his admission he was monitored in the step-down cardiac unit and relevant investigations included determination of serial creatine phosphokinase-MB fractions, a resting and 24-hour ambulatory electrocardiogram and an echocardiogram. He returned to work the day after discharge from the hospital and lost only 3 days from work. The total cost was $\$ 10,223$, which is less than $33 \%$ of the cost of surgical ablation.
In conclusion, for patients with a posteroseptal accessory pathway who require definitive therapy, it is cost effective to offer catheter ablation as the initial therapy of choice. This method has a $70 \%$ chance of success and results in substantial direct and indirect reductions in cost. Although the cost factor is neither the first nor the only issue that should influence clinical decision-making, in the present climate of financial stringencies within the health care industry, it is a significant consideration. For the minority of patients in whom catheter ablation is ineffective, surgical ablation can be performed at a total cost that is still substantially less than if surgical ablation were the primary therapy in all patients.

Acknowledgment: We wish to express our appreciation to Wendy Henshaw and the staff of Internal Medicine Associates, the patient accounts department and the medical records department of the University of Michigan Medical Center.

\section{REFERENCES}

1. Morady F, Scheinman MM. Transvenous catheter ablation of a posteroseptal accessory pathway in a patient with the Wolff-Parkinson-White syndrome. $N$ Engl J Med 1984;310:705-707.

2. Morady F, Scheinman MM, Kou WH, Griffin JC, Dick M II, Herre J, Kadish $\mathrm{AH}$, Langberg $\mathbf{J}$. Long-term results of catheter ablation of a posteroseptal accessory atrioventricular connection in 48 patients. Circulation 1989;79:1160-1170. 3. Cain ME, Cox JL. Surgical treatment of supraventricular tachyarrhythmias. In: Platia EV, ed. Management of Cardiac Arrhythmias - The Nonpharmacologic Approach. Philadelphia: J.B. Lippincott, 1987:304-339.

4. Guiraudon GM, Klein GJ, Sharma AD, Yee R, McLellan DG. Pineda EA. Surgery for Wolff-Parkinson-White syndrome using the epicardial approach. Experience with 200 patients (abstr). JACC 1988;11:110A.

5. Warin JF, Haissaguerre M, Lemetayer P, Guillem JP, Blanchot P. Catheter ablation of accessory pathways with a direct approach. Results in 35 patients. Circulation 1988;78:800-815.

6. Josephson ME, Seides SF. Clinical Cardiac Electrophysiology. Techniques and Interpretations. Philadelphia: Lea \& Febiger, 1979,211-245.

7. US Department of Commerce, Bureau of the Census. Selected per capita income and product items: 1929 to 1987. Statistical Abstract of the United States, 109th edition: $1989 ; 424$

8. Ku HH. Notes on the use of propagation of error formulas. J Res Natl Bur Stand 1966;70C:33l-34I. 